\title{
Case Report: N-Acetylcysteine Overdose: A Case Report
}

\author{
Karim Naraki ${ }^{1}$ (D), Seyed Hadi Mousavi ${ }^{2}$ (D) Leila Etemad $^{3}$, Seyed Mohsen Rezazadeh-Shojaie ${ }^{4}$, Toktam Sadeghi ${ }^{5}$, Mohammad Moshiri $^{2^{*}}$ \\ 1. Department of Pharmacodynamy and Toxicology, School of Pharmacy, Mashhad University of Medical Sciences, Mashhad, Iran. \\ 2. Medical Toxicology Research Center, Faculty of Medicine. Mashhad University of Medical Sciences, Mashhad, Iran \\ 3. Pharmaceutical Research Center, Pharmaceutical Technology Institute, Mashhad University of Medical Sciences, Mashhad, Iran. \\ 4. Legal Medicine Research Center, Legal Medicine Organization, Tehran, Iran. \\ 5. Department of Internal Medicine, Poorsina Hospital, North Khorasan University of Medical Sciences, Bojnurd, Iran.
}

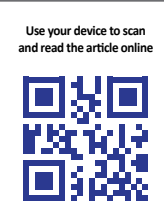

Crtation: Naraki K, Mousavi SH, Etemad L, Rezazadeh-Shojaie SM, Sadeghi T, Moshiri M. N-Acetylcysteine Overdose : A Case Report. International Journal of Medical Toxicology and Forensic Medicine. 2021; 11(1):32409. https://doi.org/10.32598/ ijmtfm.v11i.32409

https://doi.org/10.32598/ijmtfm.v11i.32409

\section{(c) (1) (3)}

Article info:

Received: 28 Sep 2020

First Revision: 13 Oct 2020

Accepted: 23 Jan 2021

Published: 8 Feb 2021

\section{Keywords:}

Medical error; Aluminum phosphate, N-Acetylcysteine, adverse drug reaction, Poisoning

\section{ABSTRACT}

Background: N-Acetylcysteine (NAC) is a cost-effective antioxidant and very useful treatment for several diseases.

Methods:Here we report a rare case of iatrogenic NAC overdose following the mistake in calculation of the loading dose.

Results:The patient was 14 years old girl referred to a local hospital due to history of intentional ingesting about 7grams acetaminophen. The physician prescribed her 6 grams $\mathrm{NAC}$ as a loading dose but 42grams NAC were infused by mistake. After infusion, the patient showed signs of anaphylactic shock and then transferred to Imam Reza toxicology-unite with weakness, lethargy, extreme fatigue, nausea, and dizziness. NAC overdosing, in a short period of time, led to coagulopathy, reduced platelet count, acute renal failure and metabolic acidosis. After $24 \mathrm{~h}$, the patient died. The Medical forensic examination showed minor lung hemorrhage and presence of little amount of Aluminum phosphide in tissues they did not find no vital organ hemorrhage. It is unclear related to NAC overdose, phosphine intoxication or synergic effects.

Conclusion: Massive transfusion of NAC was associated with impairment of coagulation factors, intracranial hypertension, renal failure and metabolic acidosis. Thus, NAC administration should be with caution. The medical history of patients committed suicide are not always accurate and complete evaluation are recommended.

\section{Introduction}

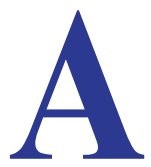

cetaminophen (APAP), also known as paracetamol, is a popular analgesic. APAP overdose can often occur because it is a common medication [1]. The liver metabolizes APAP to a hepatotoxic metabolite, $\mathrm{N}$ acetyl-p-benzoquinone imine (NAPBQI) [2] .
$\mathrm{N}$-Acetylcysteine (NAC) is a cost-effective antioxidant and proper treatment for the patient with fibrosis, chronic obstructive pulmonary disease, acetaminopheninduced hepatotoxicity [3] and several other conditions. NAC is a cysteine precursor that activates the cysteineglutamate exchanger, stimulates glutathione biosynthesis, increases detoxification, and directly scavenges free radicals [4]. These properties make NAC a well-known

* Corresponding Author:

Mohammad Moshiri, MD; PhD.

Address: Medical Toxicology Research Center, Mashhad University of Medical Sciences. Mashhad, Iran

Tel: +98 (915) 3416590

E-mail:moshirimo@gmail.com 
antioxidant. In this case report, we present a rare case of iatrogenic NAC overdose following the mistake in calculating infused dose.

\section{Case Report}

A 14-year-old girl was referred to the local hospital $2 \mathrm{~h}$ after her suicidal attempt. She said that she intentionally ingested $7 \mathrm{~g}$ of acetaminophen. She had no history of hospitalizations, liver disease, seizures, drug or ethanol abuse, and psychiatric problem. Her body weight was about $50 \mathrm{~kg}$. As the local hospital could not assess the acetaminophen serum level, the infusion of $6 \mathrm{~g}$ NAC over one hour was ordered. Each NAC ampoule in Iranian pharmacopeia contains $2 \mathrm{~g} / 10 \mathrm{~mL}$ (200 mg).

\section{Result}

Because of a wrong assumption of $200 \mathrm{mg}$ in each vial, about $42 \mathrm{~g}$ of NAC (21 vials) were infused into the patient. During the infusion, an NAC hypersensitivity reaction occurred because the patient showed drowsiness, nausea, vomiting, respiratory distress, and tachypnea. Thus the NAC infusion was discontinued, and she received chlorphenamine, hydrocortisone, and epinephrine. After $8 \mathrm{~h}$ of stay in the local hospital, she referred to the tertiary poisoning department (at $8 \mathrm{am}$ ) due to an NAC overdose. Her initial assessment in the poisoning ward was as follows: Glasgow Coma Scale $=13$, blood pressure: 90/50 $\mathrm{mm} \mathrm{Hg}$, heart rate: 130 beats/min, respiratory rare: 20 breaths/min, $\mathrm{SpO} 2: 87 \%$, temperature: $37.2^{\circ} \mathrm{C}$, and blood sugar: $86 \mathrm{mg} / \mathrm{dL}$. The electrocardiogram showed sinus tachycardia with normal QRS and corrected QT (QTc) intervals. The patient was monitored and received oxygen $6-8 \mathrm{~L} / \mathrm{min}$ by a mask. The routine toxicology evaluation, including acetaminophen serum level and urine immunoassay screen tests, were negative. Table 1 summarized the lab test results.

The Venous Blood Gas (VBG) revealed metabolic acidosis with high base excess. Therefore, she was treated with sodium bicarbonate $7.5 \%, 100 \mathrm{~mL}$ as a loading dose, and an infusion of $150 \mathrm{~mL}$ every $8 \mathrm{~h}$. A single dose of $2.5 \mathrm{mg}$ oral tablet of vitamin $\mathrm{K}$ was given because of the increased International Normalized Ratio (INR) and Prothrombin Time (PT). She was admitted to the Intensive Care Unit (ICU) $5 \mathrm{~h}$ after her admission (1 pm). Her vital signs were normal till $5 \mathrm{pm}$, but her arterial blood gas measurements indicated an unknown source of metabolic acidosis. Her hemoglobin level and platelet counts decreased. She became hypotensive $(70 / 40 \mathrm{~mm})$, and her metabolic acidosis deteriorated. She was treated with $100 \mathrm{~mL}$ of sodium bicarbonate $7.5 \%$ and an infu- sion of norepinephrine $(2-5 \mu \mathrm{g} / \mathrm{kg} / \mathrm{min})$. She developed tachypnea $(\mathrm{RR}=30)$, and her level of consciousness decreased to a GCS of 7/15; therefore, she was intubated at $8 \mathrm{pm}$. During her stay in the ICU, the patient became oliguric, with less than $100 \mathrm{~mL}$ of urine in $12 \mathrm{~h}$. At $9 \mathrm{pm}$, her respiratory tract secretions significantly increased, and the bloody discharge was seen in the tracheal tube. Then her radial pulse became impalpable, and biochemistry assays showed increased blood urea nitrogen and creatinine. The vital signs during ICU admission are presented in Table 2.

At $10 \mathrm{pm}$, she became bradycardic, which lead to asystole, and then Cardiopulmonary Resuscitation (CPR) was immediately performed. After 10 minutes, spontaneous heartbeats were detected. Metabolic acidosis was seen again, and $100 \mathrm{~mL}$ sodium bicarbonate was infused. Thirty minutes later, at $11 \mathrm{pm}$, asystole was detected again, and 30 minutes of CPR was done successfully. Ten minutes later, she became asystole for the third time. Unfortunately, 45 minutes of standard CRP was unable to resuscitate her, and she died. The corpse was transferred to the Forensic Medical Organization for further evaluation. The organization reported minor pulmonary hemorrhage and no bleeding in other vital organs. Also, they found a small amount of Aluminum Phosphide (ALP) in the stomach contents.

\section{Discussion}

We reported a 14-year-old girl who received 42 g NAC instead of $6 \mathrm{~g}$ because of the total dose miscalculation. She received 21 vials, seven times more than the prescribed dose. In APAP overdose, NAC is loaded $150 \mathrm{mg} / \mathrm{kg}$ in 200 $\mathrm{mL}$ over $60 \mathrm{~min}$ followed by $50 \mathrm{mg} / \mathrm{kg}$ in $500 \mathrm{~mL}$ over $4 \mathrm{~h}$ and, $100 \mathrm{mg} / \mathrm{kg}$ in $1000 \mathrm{~mL}$ over the next $16 \mathrm{~h}$ [5]. NAC has been introduced as an antidote and treatment of APAP intoxication to prevent hepatotoxicity [6]. The most common reported NAC adverse effects in therapeutic doses are rash, pruritus, angioedema, bronchospasm, tachycardia, and hypotension [7-9]. The current case manifested drowsiness, nausea, vomiting, respiratory distress, and tachypnea during the NAC infusion. She developed metabolic acidosis, severe hypotension, and renal failure during her hospitalization. Also, her lab tests showed increased PT and INR and decreased platelet count.

There are some case reports about NAC overdose that all of them were secondary to miscalculation. Mahmoudi et al. [10] reported a case of NAC overdose (100 g) in a 23-year-old female following intentional ingestion of $16 \mathrm{~g}$ of acetaminophen. She was intubated due to a decreased level of consciousness, severe hypotension, and 
Table 1. The lab test results of patient intoxicated by N Acetyl Cysteine referred to Imam Reza Hospital Toxicology Department.

\begin{tabular}{|c|c|c|c|c|c|}
\hline \multirow{2}{*}{$\begin{array}{c}\text { Time } \\
\text { Lab test (unite) }\end{array}$} & \multirow{2}{*}{ Local Clinic Lab Tests } & \multicolumn{4}{|c|}{ After Admission } \\
\hline & & 9 am & 17 pm & $21 \mathrm{pm}$ & 23 pm \\
\hline White blood cells $(\times 1,000)$ & - & 30.8 & 34 & - & 44 \\
\hline Hemoglobin (mg/dL) & - & 14 & 12.2 & - & 12 \\
\hline Platelets $(\times 1,000)$ & - & 144 & 114 & - & 120 \\
\hline Urea (mg/dl) & 25 & 30 & - & - & 55 \\
\hline Creatinine (mg/dl) & 0.70 & 1.4 & - & - & 3.4 \\
\hline Sodium (mEq/L) & 139 & 144 & - & 145 & - \\
\hline Potassium (mEq/L) & 3.5 & 3.4 & - & 4 & - \\
\hline Aspartate aminotransferase (U/L) & 13 & 28 & - & - & - \\
\hline Alanine aminotransferase (U/L) & 10 & 8 & - & - & - \\
\hline Alkaline phosphatase (U/L) & 540 & 206 & - & - & - \\
\hline Lactate dehydrogenase (U/L) & - & 668 & - & - & - \\
\hline Creatine phosphokinase (U/L) & - & 642 & - & - & - \\
\hline prothrombin time (seconds) & - & 22 & - & 18 & - \\
\hline international normalized ratio (INR) & - & 2.68 & - & 2.05 & - \\
\hline partial thromboplastin time(seconds) & - & 76 & - & 55 & - \\
\hline $\mathrm{pH}$ & - & 7.18 & 7.25 & 7.06 & - \\
\hline $\mathrm{PCO} 2(\mathrm{mmHg})$ & - & 40 & 31 & 54 & - \\
\hline $\mathrm{HCO} 3(\mathrm{mEq} / \mathrm{L})$ & - & 14 & 13 & 15.4 & - \\
\hline O2 sat(\%) & - & 47.4 & 36.5 & 40.6 & - \\
\hline Pco2 (mmHg) & - & 27.1 & 31.7 & 54.6 & - \\
\hline Base excess & - & -8.1 & -6.7 & -15.7 & - \\
\hline
\end{tabular}

Table 2. The vital sings of the patient intoxicated by N-Acetyl Cysteine

\begin{tabular}{|c|c|c|c|c|c|c|}
\hline Time Parameter (unite) & 13 pm & 15 pm & 17 pm & 19 pm & $21 \mathrm{pm}$ & 23 pm \\
\hline Glasgow Coma Scale & 13 & 13 & 12 & 9 & 8 & 6 \\
\hline Blood pressure (mmHg) & $100 / 60$ & $105 / 65$ & $95 / 60$ & $87 / 55$ & $80 / 53$ & $85 / 58$ \\
\hline Respiratory rate (cycle / min) & 24 & 25 & 30 & 32 & 32 & 35 \\
\hline Heart rate (beat/ min) & 130 & 128 & 133 & 125 & 135 & 145 \\
\hline Spo2 (\%) & $92 \%$ & $93 \%$ & $92 \%$ & $89 \%$ & $86 \%$ & $84 \%$ \\
\hline
\end{tabular}


tachypnea. The error in calculating the prescribed dose leads to death in ICU 12 days later due to hemolysis, thrombocytopenia, renal failure, and metabolic acidosis. In another case, a 2.5 years old boy developed delirium and seizures that progressed to cerebral edema and ultimately, severe brain injury due to an iatrogenic overdose of NAC [11]. The impaired consciousness, reduced visual acuity, and repetitive intractable focal and generalized convulsions have been reported secondary to the NAC overdose after the infusion of $20 \mathrm{~g}$ instead of $2 \mathrm{~g}$. The child was discharged in good condition after 3 days [12]. Our patient died just 2 days after admission, and it is unclear whether it was related to NAC overdose, phosphine intoxication, or synergic effects.

Although our patient showed some coagulopathy level ( $\mathrm{INR}=2.6$ ), the corps laparotomy did not find any vital organ hemorrhage or coagulopathy evidence. However, impairment of coagulation factors can be related to severe liver injures secondary to APAP toxicity; previous studies demonstrated NAC-induced coagulopathy. Intravenous NAC administration, $150 \mathrm{mg} / \mathrm{kg}$, resulted in impaired blood clotting and attenuated platelet aggregation in patients undergoing repair of abdominal aortic aneurysm [13]. Wijeysundera et al. (2009) reported that the administration of NAC to patients who underwent cardiac surgery with moderate preoperative renal insufficiency induced more blood lost and increased the amount of blood product transfused [14]. In vitro study has shown that PT increases with increasing dose of NAC [15]. NAC infusion (10 $\mathrm{mg} / \mathrm{kg}$ as a loading dose and $10 \mathrm{mg} / \mathrm{kg} / \mathrm{h}$ as continuous doses for $32 \mathrm{~h}$ ) could decrease the activity of coagulating factors, including VII, and IX without any effect on Activated Partial Thromboplastin time (APTT) [16]. Decreasing in plasma levels of other vitamin $\mathrm{K}$ dependent proteins participating in the coagulation cascade, such as factor IX, protein $\mathrm{C}$ and free protein $\mathrm{S}$, were also reported as a consequence of NAC administration $[16,17]$. NAC could reversibly reduce disulfide bonds required for maintenance coagulation factors structure and function [18]. Also, NAC reduces the activity of the vitamin $\mathrm{K}$ dependent proteins through denitrosylating [19].

Our patient became drowsy, and her cognition was impaired without any seizures. Animal studies and case reports suggested that NAC overdose causes increased internal cranial pressure leading to edema and seizure $[12,20]$.

ALP intoxication was reported as the main cause of her death by the Legal Medical Organization (LMO). They found the ALP in her tissues and pulmonary hemorrhage, similar to AIP intoxication [21]. ALP is a cheap and effective pesticide that, unfortunately, is used for suicide [22]. ALP inhibits cytochrome c oxidase (complex IV) [23]. The main complications of ALP intoxication are hypotension and metabolic acidosis [24, 25], as in our case. Disseminated Intravascular Coagulation (DIC), coagulopathy, and renal failure are not common in ALP toxicity [26] except in end stages and very severe cases. Our patient had evidence of coagulopathy, a renal failure that seems both are not related to ALP intoxication.

\section{Conclusion}

In conclusion, massive transfusion of NAC was associated with the impairment of coagulation factors, intracranial hypertension, renal failure, and metabolic acidosis. The additional doses of NAC should be administered with caution. The medical history of patients who committed suicide is not always accurate, and a complete evaluation is recommended.

\section{Ethical Considerations}

\section{Compliance with ethical guidelines}

All ethical principles are considered in this article. The participants were informed of the purpose of the research and its implementation stages. Also, Informed consent was obtained from the parents of the deceased child.

\section{Funding}

This research did not receive any grant from funding agencies in the public, commercial, or non-profit sectors.

\section{Author's contributions}

Conceptualization and Supervision: Mohammad Moshiri; Methodology: Leila Etemad; Investigation, Writing original draft, and Writing review \& editing: All authors; Data collection: Seyed Hadi Mousavi, Seyed Mohsen Rezazadeh-Shojaie, Toktam Sadeghi, and Mohammad Moshiri; Funding acquisition and Resources: Mohammad Moshiri.

\section{Conflict of interest}

The authors declared no conflict of interests.

\section{Acknowledgements}

The authors would like to thank the parents of the deceased girl for their agreement of publication. We would like to thank the staff of Mashhad Legal Medicine Or- 
ganization and the staff of the Poisoning Ward of Imam Reza Hospital for their kind cooperation as well.

\section{References}

[1] Lee WM. Acetaminophen (APAP) hepatotoxicity-Isn't it time for APAP to go away? J Hepatol. 2017; 67(6):1324-31. [DOI:10.1016/j.jhep.2017.07.005] [PMID] [PMCID]

[2] Beltrán-Olazábal A, Martínez-Galán P, Castejón-Moreno R, García-Moreno ME, García-Muro C, Esteban-Zubero E. Management of acetaminophen toxicity: A review. Iberoamerican J Med. 2019; 1(1):22-8. http://dx.doi. org/10.5281/zenodo.3470262

[3] Sanguinetti CM. N-acetylcysteine in COPD: Why, how, and when? Multidiscip Respir Med. 2015; 11:8. [DOI:10.1186/ s40248-016-0039-2] [PMID] [PMCID]

[4] Tunek A. Possible mechanisms behind the anti-inflammatory effects of $\mathrm{N}$-acetyl cysteine: Is metabolism essential? Eur Respir Rev. 1992; 2(7):35-8.

[5] Yarema MC, Johnson DW, Berlin RJ, Sivilotti ML, NettelAguirre A, Brant RF, et al. Comparison of the 20-hour intravenous and 72-hour oral acetylcysteine protocols for the treatment of acute acetaminophen poisoning. Ann Emerg Med. 2009; 54(4):606-14. [DOI:10.1016/j.annemergmed.2009.05.010] [PMID]

[6] Keays R, Harrison PM, Wendon JA, Forbes A, Gove C, Alexander GJ, et al. Intravenous acetylcysteine in paracetamol induced fulminant hepatic failure: A prospective controlled trial. BMJ. 1991; 303(6809):1026-9. [DOI:10.1136/ bmj.303.6809.1026] [PMID] [PMCID]

[7] Wright RO, Perry HE, Woolf AD, Shannon MW. Hemolysis after acetaminophen overdose in a patient with glucose6-phosphate dehydrogenase deficiency. J Toxicol Clin Toxicol. 1996; 34(6):731-4. [DOI:10.3109/15563659609013837] [PMID]

[8] Kanter MZ. Comparison of oral and i.v. acetylcysteine in the treatment of acetaminophen poisoning. Am J Health Syst Pharm. 2006; 63(19):1821-7. [DOI:10.2146/ajhp060050] [PMID]

[9] Brok J, Buckley N, Gluud C. Interventions for paracetamol (acetaminophen) overdose. Cochrane Database Syst Rev. 2006; (2):CD003328. [DOI:10.1002/14651858.CD003328. pub2] [PMID]

[10] Mahmoudi GA, Astaraki P, Mohtashami AZ, Ahadi M. $\mathrm{N}$-acetylcysteine overdose after acetaminophen poisoning. Int Med Case Rep J. 2015; 8:65-9. [DOI:10.2147/IMCRJ. S74563] [PMID] [PMCID]

[11] Heard K, Schaeffer TH. Massive acetylcysteine overdose associated with cerebral edema and seizures. Clin Toxicol (Phila). 2011; 49(5):423-5. [DOI:10.3109/15563650.2011.5836 64] [PMID]

[12] Razlansari AA, Jafrasteh A, Garmsiri M. N-Acetylcysteine overdose after acetaminophen poisoning. Int J Adv Biol Biomed Res. 2017; 5(2):69-72. [DOI:10.26655/ijabbr.2017.3.4]
[13] Niemi TT, Munsterhjelm E, Poyhia R, Hynninen MS, Salmenpera MT. The effect of N-acetylcysteine on blood coagulation and platelet function in patients undergoing open repair of abdominal aortic aneurysm. Blood Coagul Fibrinolysis. 2006; 17(1):29-34. [DOI:10.1097/01. mbc.0000195922.26950.89] [PMID]

[14] Wijeysundera DN, Karkouti K, Rao V, Granton JT, Chan $\mathrm{CT}$, Raban R, et al. N-acetylcysteine is associated with increased blood loss and blood product utilization during cardiac surgery. Crit Care Med. 2009; 37(6):1929-34. [DOI:10.1097/CCM.0b013e31819ffed4] [PMID]

[15] Pizon AF, Jang DH, Wang HE. The in vitro effect of Nacetylcysteine on prothrombin time in plasma samples from healthy subjects. Acad Emerg Med. 2011; 18(4):351-4. [DOI:10.1111/j.1553-2712.2011.01041.x] [PMID]

[16] Jang DH, Weaver MD, Pizon AF. In vitro study of Nacetylcysteine on coagulation factors in plasma samples from healthy subjects. J Med Toxicol. 2013; 9(1):49-53. [DOI:10.1007/s13181-012-0242-2] [PMID] [PMCID]

[17] Jepsen S, Hansen AB. The influence of N-acetylcysteine on the measurement of prothrombin time and activated partial thromboplastin time in healthy subjects. Scand J Clin Lab Invest. 1994; 54(7):543-7. [DOI:10.3109/00365519409088566] [PMID]

[18] Kim KY, Rhim T, Choi I, Kim SS. N-acetylcysteine induces cell cycle arrest in hepatic stellate cells through its reducing activity. J Biol Chem. 2001; 276(44):40591-8. [DOI:10.1074/ jbc.M100975200] [PMID]

[19] Marley R, Patel RP, Orie N, Ceaser E, Darley-Usmar V, Moore K. Formation of nanomolar concentrations of S-nitroso-albumin in human plasma by nitric oxide. Free Radic Biol Med. 2001; 31(5):688-96. [DOI:10.1016/S0891-5849(01)00627$\mathrm{X}]$

[20] Miller LF, Rumack BH. Clinical safety of high oral doses of acetylcysteine. Semin Oncol. 1983; 10(1 Suppl 1):76-85. https:/ / d1wqtxts1xzle7.cloudfront.net/50770520/100_Miller_Rumack_1983_Safety_Hi_Dose_NAC_Semin_Oncology.pdf?

[21] Taromsar MR, Teymourpour P, Jahanbakhsh R. [Survey the histopathological findings in autopsy of poisoned patients with rice tablet (Aluminium Phosphide) (Persian)] J Guilan Univ Med Sci. 2011; 19(76):56-63. http://journal. gums.ac.ir/article-1-171-en.html

[22] Chugh SN. Aluminium phosphide poisoning: present status and management. J Assoc Physicians India. 1992;40(6):401-5. [PMID]

[23] Dua R, Gill KD. Effect of aluminium phosphide exposure on kinetic properties of cytochrome oxidase and mitochondrial energy metabolism in rat brain. Biochim Biophys Acta. 2004; 1674(1):4-11. [DOI:10.1016/j.bbagen.2004.05.003] [PMID]

[24] Arora B, Punia RS, Kalra R, Chugh SN, Arora DR. Histopathological changes in aluminium phosphide poisoning. J Indian Med Assoc. 1995;93(10):380-1. [PMID]

[25] Sinha US, Kapoor AK, Singh AK, Gupta A, Mehrotra $R$. Histopathological changes in cases of aluminium phosphide poisoning. Indian J Pathol Microbiol. 2005;48(2):17780. [PMID] 
[26] SinghS, Singh D, Wig N, Jit I, Sharma BK. Aluminum phosphide ingestion--a clinico-pathologic study. J Toxicol Clin Toxicol.1996;34(6):703-6. [DOI:10.3109/15563659609013832] [PMID] 